Humanities and Social Sciences Letters

2021 Vol. 9, No. 4, pp. 351-361.

$\operatorname{ISSN}(e): 2312-4318$

$\operatorname{ISSN}(p): 2312-5659$

DOI: 10.18488/journal.73.2021.94.351.361

(C) 2021 Conscientia Beam. All Rights Reserved.

check for
updates

\title{
PSYCHOLOGICAL REACTIONS IN A SAMPLE FROM SAUDI ARABIA DURING THE COVID-19 PANDEMIC
}
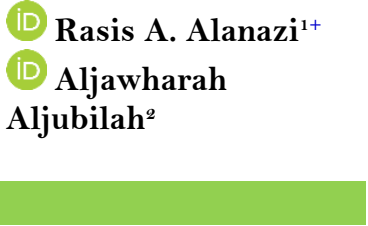

Article History

Received: 16 February 2021 Revised: 2 September 2021

Accepted: 8 October 2021

Published: 5 November 2021

\section{Keywords}

Psychological reactions

COVID-19

Depression

Insomnia

Anxiety

Mental health.

\author{
${ }_{1,2}^{1,2}$ Department of Psychology, School of Education; Princess Nourah bint \\ Abdulrahman University, Riyadh, Saudi Arabia. \\ Email:rasisalanazi@gmail.com Tel: +966505811655 \\ 'Email:aljobelah@gmail.com Tel: +966555117435
}

ABSTRACT

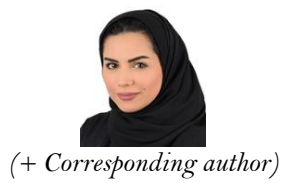

The sudden outbreak of the COVID-19 pandemic has raised many concerns regarding people's physical and mental health. The aim of the study is to examine the levels of depression, anxiety, and insomnia. Demographic variables were examined (gender, age, educational level, and work) in relation to depression, anxiety, and insomnia. An online survey was sent to individuals who voluntarily participated in the study anonymously, and a total of 531 people were recruited from Saudi Arabian society (355 females, 176 males). Several analyses were used to detect the levels of depression, anxiety, and insomnia and results revealed low levels of depression, anxiety, and insomnia. Anxiety levels in females were higher compared to males; educational level was negatively correlated to depression and anxiety; there was a negative correlation between age and the levels of depression and anxiety; and younger participants reported higher levels of depression and anxiety. In addition, students were more likely to suffer from insomnia compared to employees in both public and private sectors, unemployed participants had higher anxiety levels compared to employees; and finally, a statistically significant difference was found between levels of depression, anxiety and insomnia. Predictions for insomnia can be detected from depression and anxiety variables.

Contribution/Originality: The paper's primary contribution is finding the psychological impact of COVID-19 on participants' mental health and well-being at early stages in Saudi Arabia. The study examined three aspects of mental health - depression, anxiety and insomnia - in relation to participants' age, gender educational level, and work status. The study examined individuals' mental well-being during governmental lock down across Saudi in an attempt to better understand the changes on one's overall mental health.

\section{INTRODUCTION}

During late December 2019, a novel case of pneumonia of unknown origin was reported in Wuhan City, Hubei Province, China. Later, this unknown disease was identified as an acute respiratory illness with unidentified cause (Wuhan City Health Committee (WCHC), 2020). A month later, the disease has spread throughout Chinese cities and recently and by January, 2020 the number of confirmed cases have reached 86,986 in China (Saudi Center for Disease Prevention and Control, 2020). The World Health Organization (WHO) have officially named it coronavirus disease 2019 (COVID-19). The COVID-19 outbreak was declared an international emergency.

The disease is related to (SARS-CoV-2) and has similar features by which the disease can be transmitted, e.g., via human-to-human interaction. Symptoms experienced by COVID-19 patients included fever, chills, trouble breathing, nausea, vomiting, and a persistent cough (Chen et al., 2020). In severe cases, the disease may result in 
respiratory failure, acute distress, and death (Holshue et al., 2020). The risk of infection is higher in the elderly, in people with medical conditions, and in people with a weak immune system (Saudi Center for Disease Prevention and Control, 2020).

It was announced that COVID-19 had spread globally to 150 countries, around 7,000 deaths were confirmed (WHO), and on March 11, 2020, the COVID-19 outbreak was declared by the WHO as a pandemic. The number of confirmed cases in Saudi Arabia on May 27, 2020 had reached 78,657 cases and around 441 deaths had been confirmed (World Health Organization, 2020).

\subsection{Precautionary Measures}

Since the outbreak, several countries around the world have made massive efforts to illuminate control the spread of the disease. Enormous efforts have been made in Saudi Arabia to control the spread of COVID-19; a lockdown was effective, and travel restrictions were put in place. In accordance with the Saudi Vision 2030 in establishing a positive community and healthy individuals (The Kingdom of Saudi Arabia Vision 2030 Strategic Objective and the Vision Realization programs), different measures were established. The mode of communication was shifted to online platforms, employees and students worked remotely, and businesses were allowed to continue operating according to new precautionary measures and changes were made accordingly. Confirmed cases were treated in hospitals and suspected cases were quarantined in hotels. Different communication channels were used to update individuals with the information via media, news, podcasts, and daily conferences held by the Ministry of Health on national television to report statistics on cases (Saudi Press Agency). There were several changes made to air and land traffic, land ports between the Kingdom and other countries were limited to commercial trucks, and all flights were restricted to emergency cases. In accordance with precautionary measures set out by health authorities in Saudi, and to ensure pilgrims' safety, Umrah was postponed until further notice.

\subsection{Depression}

The fast spread of the disease, sudden changes in people's lifestyles, and the risk of becoming infected have had a huge impact on people's psychological reactions towards the pandemic. There have been several studies that reported the pandemic's psychological impact on people (Chen et al., 2020; Li et al., 2020; Yang et al., 2020). According to Ho, Chee, \& Ho (2020), the epidemic can trigger psychiatric symptoms such as anxiety and depression.

These psychological changes include anxiety, mood disorders, depression, panic attacks, fear, anger, and aggression. Anxiety and mood disorders especially are common among people globally (Prince et al., 2007).

\subsection{Insomnia}

The study aims to identify the relationship between depression, anxiety, and insomnia during the pandemic. Several previous studies have examined the global outbreak impact on several psychological disorders such as anxiety, insomnia, and depression.

Insomnia is difficulty in falling or staying asleep and negatively impacts sleep quality (Nutt \& Ballenger, 2007). It is a sleep disorder that affects about 10\% of the general population (Drake \& Pillai, 2017) and is characterized by sleep disturbance. Symptoms of insomnia include difficulty falling asleep at night, waking up during the night, waking up too early, not feeling comfortable after sleeping at night, fatigue during the day, feeling sleepy, anxious, or depressed, difficulties focusing on tasks, poor concentration, focusing on mistakes or frequent incidents, and constant anxiety about sleep (Harris et al., 2015; Kyle \& Espie, 2014).

In addition to the significant distress and dysfunction caused by these symptoms, individuals with insomnia are also at risk of various forms of medical and psychiatric morbidity, including hypertension and depression. The past decade has witnessed several important advances in the conceptualization, diagnosis, and etiology of this disorder 
(Koranyi, Meinhard, Bublak, Witte, \& Rupprecht, 2018). In the Diagnostic and Statistical Manual of Mental Disorders, 5th Edition (DSM-5), chronic insomnia is described as problems initiating and staying asleep for at least three days a week for three or more months. Furthermore, these sleep problems need to have a negative effect on daytime functioning (Ohayon, 2002). Chronic insomnia has a major influence on mental and psychosocial well-being and predisposes sufferers to serious medical and psychological consequences, including higher rates of cardiovascular, metabolic, and psychiatric diseases. It may also result in poor mental health (American Psychiatric Association, 2013). Insomnia is also associated with high socioeconomic burden as well as vulnerability to the development of mental and physical health problems (Baglioni et al., 2011).

\subsection{Anxiety}

The past decade has seen increased interest and research into anxiety disorders, largely because of a greater recognition of their burden and the implications associated with untreated illness. Clinical reviews have shown that the presence of an anxiety disorder is a risk factor for the development of other anxiety and mood disorders and substance abuse. In clinical and population-based studies, the development of comorbidities makes the treatment of primary and secondary disorders difficult, contributes to low remission rates, poor prognosis, and risk of suicide. (Nutt \& Ballenger, 2007; Simpson, Neria, Lewis-Fernández, \& Schneier, 2010). Unfortunately, anxiety disorders are common. Research shows that up to one in four adults suffers from an anxiety disorder some time in their life, and that one person in ten is likely to have had an anxiety disorder in the past year. Anxiety disorders are the most common mental health problem in women and are second only to substance abuse disorders in men. Anxiety disorders can make it hard for people to work or study, manage daily tasks, and interact with others, and often result in financial strain and profound personal suffering. Anxiety-affected youths also tend to be at greater risk of suicidal ideation and behaviors than their peers without an anxiety diagnosis (Gallagher, Prinstein, Simon, \& Spirito, 2014). Over 95\% of youths living with anxiety experience at least one somatic symptom including headache, stomach ache, head cold or sniffles, sleeplessness, or feelings of drowsiness (Crawley et al., 2014). Anxiety-affected youths may worry about seemingly everyday tasks as well as the sights and sounds of everyday life (Woodgate, Zurba, Edwards, Ripat, \& Rempel, 2017), about feeling different, and about their social relationships. They may also worry about their health and the health of others, their performance in school or extracurricular activities, as well as fears related to disasters (e.g., hurricanes) and other external events that could threaten their well-being (Woodgate et al., 2017). Sufferers of anxiety can experience other physiological symptoms including fatigue, dizziness, headaches, nausea, abdominal pain, palpitations, shortness of breath, and urinary incontinence (Testa et al., 2013).

\section{MATERIALS METHODS}

\subsection{Study Sample and Methods}

An online questionnaire was sent to participants across Saudi Arabia at early stages of the pandemic. Upon agreement to participate voluntarily, they filled in the questionnaire that took approximately 15 minutes to complete. All data collected was anonymous. A total of 531 individuals participated in the study, the majority of which were female (355 females, 176 males). In reference to Krejcie \& Morgan (1970), a sample size of 364 was required for the given population. The participants' educational level ranged from primary education to secondary level education.

\subsection{Instruments}

Depression Scale

The scale used in this study to measure depression level was Beck's Depression Inventory after translating it into Arabic. The scale consisted of a demographic section that included age, gender, academic level, and 
employment status, and a total of 13 items (see Table 1). The scale is based on a 4-point Likert rating scale ranging from 0 (not depressed) to 3 (depressed). The scale reliability and validity were tested on a sample of 92 participants from the overall study sample. Reliability of the scale was tested using Cronbach's alpha and the Spearman-Brown method. (Cronbach's a $=0.9$ ).

According to Table 1, the alpha coefficient scale when omitting each question was less than or equal to the overall alpha coefficient scale in the case of all questions. This indicates that all questions are stable. On the other hand, All the correlation coefficients between the score of each question and the overall score of the scale (in the case of the question score) are statistically significant at the level (0.01), which indicates the validity and internal consistency. Further, all the correlation coefficients between the score of each question and the total score of the scale (in case the question score is omitted) are statistically significant at the level (0.01), which indicates the reliability of the scale. Lastly, the overall reliability coefficients by Cronbach's alpha, and split half of Spearman/Brown are high, indicating the overall reliability of the scale. From the previous procedures, the reliability and validity of the depression scale were confirmed, and its valid for measuring depression in a sample of the Saudi Society.

Table-1. Correlations Coefficient of Items on the Depression Scale (N 92).

\begin{tabular}{|c|c|c|c|}
\hline Item & $\begin{array}{c}\text { Cronbach's Alpha if } \\
\text { Item Deleted }\end{array}$ & $\begin{array}{l}\text { Item-Total } \\
\text { Correlation }\end{array}$ & $\begin{array}{c}\text { Corrected Item-Total } \\
\text { Correlation }\end{array}$ \\
\hline 1 & 0.850 & $0.67 * *$ & $0.60^{* *}$ \\
\hline 2 & 0.846 & $0.72^{* *}$ & $0.65^{* *}$ \\
\hline 3 & 0.862 & $0.49^{* *}$ & $0.38 * *$ \\
\hline 4 & 0.862 & $0.53^{* *}$ & $0.41 * *$ \\
\hline 5 & 0.857 & $0.54 * *$ & $0.47 * *$ \\
\hline 6 & 0.842 & $0.76^{* *}$ & $0.69 * *$ \\
\hline 7 & 0.860 & $0.47 * *$ & $0.40^{* *}$ \\
\hline 8 & 0.848 & $0.70^{* * *}$ & $0.61^{* *}$ \\
\hline 9 & 0.855 & $0.58 * *$ & $0.51^{* *}$ \\
\hline 10 & 0.849 & $0.67 * *$ & $0.60^{* * *}$ \\
\hline 11 & 0.849 & $0.69^{* * *}$ & $0.60^{* *}$ \\
\hline 12 & 0.850 & $0.66^{* * *}$ & $0.58 * *$ \\
\hline 13 & 0.860 & $0.52^{* *}$ & $0.41^{* *}$ \\
\hline & \multicolumn{3}{|c|}{ Cronbach's alpha (13 items) $=0.863$} \\
\hline & \multicolumn{3}{|c|}{ Spearman-Brown $=0.869$} \\
\hline
\end{tabular}

\section{Insomnia Scale}

This is a self-reporting scale and was developed by Morin, Belleville, Bélanger, \& Ivers (2011) to measure the quality of sleep. It consists of seven items to assess the severity and impact of insomnia during the last month, and the dimensions evaluated are the degrees of intensity of the beginning of sleep, quality of sleep, problems waking up, dissatisfaction with sleep, and distress caused by sleep difficulties. The questionnaire is based on a 5-point Likert rating scale and the questionnaire scores range from 0 to 28 degrees.

According to Table 2, the alpha coefficient of the scale when deleting each of its terms is less than or equal to the general alpha coefficient of the scale in the case of all the items present, and this indicates that all the items are stable and valid. Further, all correlation coefficients between the item and the total scale (in case of item existence) are statistically significant at the level (0.01), which indicates the internal consistency and validity. On the other hand, All the correlation coefficients between each item and the total scale (in case of omitting the item) are statistically significant at the level (0.01), which indicates the reliability. While the coefficients of total reliability by two alpha methods for Cronbach and split half for Spearman/Brown are high, which indicates the overall reliability. From the previous procedures, the reliability and validity of the scale were confirmed, and its validity for measuring sleep disorders in a sample of Saudi society. 
Table-2. Insomnia Correlations Coefficient of Items in Insomnia Scale $(\mathrm{N}=92)$

\begin{tabular}{c|c|c|c}
\hline Item & $\begin{array}{c}\text { Cronbach's Alpha if Item } \\
\text { Deleted }\end{array}$ & $\begin{array}{c}\text { Item-Total } \\
\text { Correlation }\end{array}$ & Corrected Item-Total Correlation \\
\hline 1 & 0.866 & $0.83^{* *}$ & $0.76^{* *}$ \\
\hline 2 & 0.880 & $0.74^{* *}$ & $0.64^{* *}$ \\
\hline 3 & 0.890 & $0.68^{* *}$ & $0.55^{* *}$ \\
\hline 4 & 0.865 & $0.84^{* *}$ & $0.76^{* *}$ \\
\hline 5 & 0.882 & $0.72^{* *}$ & $0.62^{* *}$ \\
\hline 6 & 0.858 & $0.88^{* *}$ & $0.82^{* *}$ \\
\hline 7 & 0.874 & $0.78^{*}$ & $0.69^{* *}$ \\
\hline & \multicolumn{2}{|c|}{ Cronbach's Alpha $(7 \mathrm{items})=0.890$} \\
\hline
\end{tabular}

Note: $* *$ Sig. at $(\alpha=0.01)$.

\section{Anxiety Scale}

We used the General Anxiety Disorder (GAD) scale developed by Spitzer, Kroenke, Williams, \& Löwe (2006) as a screening tool and severity indicator for GAD. The scale is a 7 -item, self-rated scale, and responses are based on a 4-point Likert rating scale ranging from 0 (not at all) to 3 (nearly every day). Table 3 shows the alpha coefficient of the scale when deleting each of its items is less than or equal to the general alpha coefficient of the scale in the case of all the items present, and this indicates that all the items are stable. All correlation coefficients between each of the items and the total score of the scale (in case of item existence) are statistically significant at the level (0.01), which indicates internal validity and stability. Further, all the correlation coefficients between each item and the scale (in the case of omitting the item) are statistically significant at the level (0.01), which indicates the reliability. The coefficients of total reliability by two alpha methods for Cronbach, and split half for Spearman/Brown are high, which indicates the overall reliability. From the previous procedures, the reliability and validity of the scale were confirmed, and its valid for measuring anxiety among a sample of Saudi society.

Table-3. Anxiety Correlation Coefficient of Items on the Anxiety Scale $(\mathrm{N}=92)$.

\begin{tabular}{c|c|c|c}
\hline Item & $\begin{array}{c}\text { Cronbach's Alpha if Item } \\
\text { Deleted }\end{array}$ & Item-Total Correlation & $\begin{array}{c}\text { Corrected Item-Total } \\
\text { Correlation }\end{array}$ \\
\hline 1 & 0.892 & $0.79^{* *}$ & $0.71^{* *}$ \\
\hline 2 & 0.887 & $0.83^{* *}$ & $0.76^{* *}$ \\
\hline 3 & 0.882 & $0.86^{* *}$ & $0.80^{* *}$ \\
\hline 4 & 0.881 & $0.87^{* *}$ & $0.81^{* *}$ \\
\hline 5 & 0.905 & $0.61^{* *}$ & $0.50^{* *}$ \\
\hline 6 & 0.881 & $0.87^{* *}$ & $0.80^{* *}$ \\
\hline 7 & 0.900 & $0.76^{* *}$ & $0.65^{* *}$ \\
\hline
\end{tabular}

Note: $* *$ Sig. at $(\alpha=0.01)$.

\section{DATA ANALYSIS}

Several statistical analyses were conducted to address the research questions. Cronbach's alpha coefficient was conducted to test the validity and reliability of the scale scores; the Spearman-Brown formula was applied to estimate the reliability of the total scale; the average mean, frequencies, and percentages of depression, insomnia, and anxiety were calculated; a T-test was used to detect the differences between males and females in depression, anxiety, insomnia; and a one-way analysis followed by a least significant difference (LSD) test was conducted to detect the differences in depression, anxiety, and insomnia in relation to educational level. Finally, a multiple stepwise regression analysis was used to predict insomnia from depression and anxiety in the study sample. All analyses were conducted using SPSS $®$ software version 22.0. 


\section{RESULTS AND DISCUSSION}

Q1: To examine levels of depression, insomnia, and anxiety in the sample of the study, where the means, percentages were calculated.

According to Table 4, it shows that the highest percentage from the Saudi society sample had an average of: depression, Insomnia, and anxiety at the (low) level, where the percentage of those with a low level of depression amounted to $(87.9 \%)$, and the percentage of those with a low level of sleep disorders reached $(72.1 \%)$, and the percentage of those with a low level of anxiety was (66.5\%). Therefore, indicate that the study participants have overall low levels of depression, insomnia, and anxiety.

Table 4. The mean, percentage, and frequencies of depression, insomnia, and anxiety $(\mathrm{N}=531)$.

\begin{tabular}{|c|c|c|c|c|c|c|c|c|}
\hline \multirow{2}{*}{ Variable } & \multirow{2}{*}{ Mean } & \multirow{2}{*}{ Percentage } & \multicolumn{6}{|c|}{ Level } \\
\hline & & & No. & $\%$ & No. & $\%$ & No. & $\%$ \\
\hline Insomnia & 14.02 & $40.07 \%$ & 23 & $4.3 \%$ & 125 & $23.5 \%$ & 383 & $72.1 \%$ \\
\hline Anxiety & 12.48 & $44.57 \%$ & 55 & $10.4 \%$ & 123 & $23.2 \%$ & 353 & $66.5 \%$ \\
\hline
\end{tabular}

Q2: To detect whether the levels of depression, insomnia, and anxiety differ by gender, a t-test was conducted.

According to Table 5, there are no statistically significant differences between the averages of males and females in both depression and insomnia (P-value > 0.05). however, it could see that females were slightly higher than males in terms of involved by depression and insomnia. On the other hand, there is a statistically significant difference between males and females in anxiety in favor of the average to the females $(\mathrm{P}$-value $<0.05)$. Thus, could coney that females are more anxious than males.

Table 5. T-test to detect the differences between males and females for depression, anxiety, and insomnia

\begin{tabular}{|c|c|c|c|c|c|c|}
\hline Variable & Gender & No. & Mean & Std. Deviation & T-Value & Sig. \\
\hline \multirow{2}{*}{ Depression } & Female & 355 & 19.18 & 5.31 & \multirow{2}{*}{1.10} & \multirow{2}{*}{0.27} \\
\hline & Male & 176 & 18.65 & 5.07 & & \\
\hline \multirow{2}{*}{ Insomnia } & Female & 355 & 14.26 & 5.89 & \multirow{2}{*}{1.36} & \multirow{2}{*}{0.17} \\
\hline & Male & 176 & 13.55 & 5.34 & & \\
\hline \multirow[t]{2}{*}{ Anxiety } & Female & 355 & 12.85 & 5.50 & \multirow{2}{*}{2.29} & \multirow{2}{*}{0.05} \\
\hline & Male & 176 & 11.73 & 4.97 & & \\
\hline
\end{tabular}

Q3: To detect whether the levels of depression, insomnia, and anxiety differ by educational level, a one-way analysis of variance (ANOVA) was conducted.

According to Table 6, there are no statistically significant differences in insomnia due to the educational level (P-value > 0.05). however, there are statistically significant differences (at the level of 0.01) in depression, and anxiety due to the educational level. Thus, the lower the educational level of the individual, had higher level of depression, and anxiety.

\begin{tabular}{|c|c|c|c|c|c|c|}
\hline Variable & Education level & No. & Mean & Std. Deviation & F-Value & Sig. \\
\hline \multirow{3}{*}{ Depression } & High school or below & 82 & 20.41 & 5.89 & \multirow{3}{*}{5.37} & \multirow{3}{*}{0.01} \\
\hline & College degree & 345 & 19.00 & 5.23 & & \\
\hline & Higher education degree & 104 & 17.90 & 4.39 & & \\
\hline \multirow{3}{*}{ Insomnia } & High school or below & 82 & 14.34 & 6.05 & \multirow{3}{*}{0.36} & \multirow{3}{*}{0.70} \\
\hline & College degree & 345 & 14.06 & 5.68 & & \\
\hline & Higher education degree & 104 & 13.64 & 5.63 & & \\
\hline \multirow[t]{3}{*}{ Anxiety } & High school or below & 82 & 13.52 & 6.11 & \multirow{3}{*}{4.80} & \multirow{3}{*}{0.01} \\
\hline & College degree & 345 & 12.62 & 5.23 & & \\
\hline & Higher education degree & 104 & 11.18 & 4.92 & & \\
\hline
\end{tabular}


Q4: To detect whether the levels of depression, insomnia, and anxiety differ by age, a one-way ANOVA was conducted.

According to Table 7 , there are no statistically significant differences in insomnia due to age (P-value $>0.05)$. While there are statistically significant differences (at the level of 0.01 ) in depression, and anxiety due to age (Pvalue $<0.05)$. That is, the lower the age of the individual, the higher his level of depression and anxiety have.

Table 7. One-way ANOVA analysis to detect the differences in depression, anxiety, and insomnia in relation to age.

\begin{tabular}{|c|c|c|c|c|c|c|}
\hline Variable & Age & No. & Mean & Std. Deviation & F-Value & Sig. \\
\hline \multirow{4}{*}{ Depression } & $14-19$ & 40 & 20.98 & 4.89 & \multirow{4}{*}{8.73} & \multirow{4}{*}{0.01} \\
\hline & $20-29$ & 159 & 19.99 & 5.53 & & \\
\hline & $30-39$ & 176 & 19.04 & 5.34 & & \\
\hline & $\geq 40$ & 156 & 17.45 & 4.45 & & \\
\hline \multirow{4}{*}{ Insomnia } & $14-19$ & 40 & 15.23 & 4.69 & \multirow{4}{*}{2.45} & \multirow{4}{*}{0.06} \\
\hline & $20-29$ & 159 & 14.62 & 6.11 & & \\
\hline & $30-39$ & 176 & 14.00 & 5.81 & & \\
\hline & $\geq 40$ & 156 & 13.13 & 5.36 & & \\
\hline \multirow{4}{*}{ Anxiety } & $14-19$ & 40 & 14.23 & 5.27 & \multirow{4}{*}{4.25} & \multirow{4}{*}{0.01} \\
\hline & $20-29$ & 159 & 12.96 & 4.97 & & \\
\hline & $30-39$ & 176 & 12.64 & 5.38 & & \\
\hline & $\geq 40$ & 156 & 11.36 & 5.56 & & \\
\hline
\end{tabular}

Q5: A one-way ANOVA analysis was conducted to examine whether depression, anxiety and insomnia level differ by work status.

There are statistically significant differences (at the level of 0.01) in depression, insomnia, and anxiety due to work (P-value < 0.05), where the students are more depressed compared to governmental or self- sector employees (see Table 8). In addition, results revealed that unemployed people had high level from depression, insomnia and anxiety compared to the employed participants.

Table-8. One-way analysis to detect the differences in depression, anxiety, and insomnia in relation to work status

\begin{tabular}{|c|c|c|c|c|c|c|}
\hline Variable & Work & No. & Mean & Std. Deviation & F-Value & Sig. \\
\hline \multirow{5}{*}{ Depression } & Employed in the public sector & 168 & 17.96 & 4.81 & \multirow{5}{*}{6.76} & \multirow{5}{*}{0.01} \\
\hline & Employed in the private sector & 132 & 18.50 & 4.68 & & \\
\hline & Not employed & 101 & 19.91 & 5.46 & & \\
\hline & Student & 99 & 20.91 & 6.00 & & \\
\hline & Freelance & 31 & 17.71 & 4.26 & & \\
\hline \multirow{5}{*}{ Insomnia } & Employed in the public sector & 168 & 13.35 & 5.40 & \multirow{5}{*}{4.05} & \multirow{5}{*}{0.01} \\
\hline & Employed in the private sector & 132 & 12.98 & 5.47 & & \\
\hline & Not employed & 101 & 15.18 & 5.73 & & \\
\hline & Student & 99 & 15.30 & 6.25 & & \\
\hline & Freelance & 31 & 14.29 & 5.55 & & \\
\hline \multirow{5}{*}{ Anxiety } & Employed in the public sector & 168 & 11.69 & 4.87 & \multirow{5}{*}{5.73} & \multirow{5}{*}{0.01} \\
\hline & Employed in the private sector & 132 & 11.60 & 5.00 & & \\
\hline & Not employed & 101 & 14.09 & 6.21 & & \\
\hline & Student & 99 & 13.66 & 5.40 & & \\
\hline & Freelance & 31 & 11.52 & 4.53 & & \\
\hline
\end{tabular}

Q6: To examine the relationship between insomnia, anxiety, and depression, and to predict insomnia from anxiety and depression, a Pearson correlation coefficient test and a multiple stepwise regression analysis were conducted.

Table 9 illustrated a statistical positive relationship between the depression and anxiety on insomnia (P-value $<0.01)$.

To predict sleep disorders (insomnia) from depression and anxiety, multiple regression stepwise analysis has been used as in Table 10. The results of the multiple regression analysis led to inclusion the variable of (anxiety) in the multi-regression equation in the first step as the strongest independent variables influenced the variable (insomnia), and in the second step, a variable (depression) was included in the multiple regression analysis as a 
stronger second independent variables influenced the insomnia, and the result of this question is as statistical significant influence at 0.01 level for depression and anxiety into insomnia and sleep disorders.

Table-9. Correlation coefficient between depression, insomnia, and anxiety $(\mathrm{N}=531)$.

\begin{tabular}{c|c|c|c}
\hline Variable & Insomnia & Depression & Anxiety \\
\hline Insomnia & 1 & 1 & \\
\hline Depression & $0.59^{* *}$ & $0.69^{* *}$ & 1 \\
\hline Anxiety & $0.62^{* *}$ & & \\
\hline Note: Significant statistical correlation was found between insomnia, depression, and anxiety.
\end{tabular}

The coefficient of determination (the square of the multiple correlation coefficient) is equal to $\left(\mathrm{R}^{2}=0.433\right)$, which indicates that the depression and anxiety variables together explain $43.3 \%$ of the variance in the degrees of the dependent variable which is (Insomnia - the sleep disorders). It considers a large amount of variance that could explain by these two variables. Further, it is possible to predict insomnia or sleep disorders from the variables of depression and anxiety in the research sample from the Saudi society.

Table-10. Multiple stepwise regression analysis predicting insomnia from depression and anxiety in the study sample $(\mathrm{N}=531)$

\begin{tabular}{|c|c|c|c|c|c|c|}
\hline & Sum of Squares & df. & Mean Square & $\mathbf{F}$ & Sig. & $\mathbf{R}^{2}$ \\
\hline Regression & 7515.87 & 2 & 3757.94 & \multirow{2}{*}{201.88} & \multirow{2}{*}{0.01} & \multirow{2}{*}{0.433} \\
\hline Residual & 9828.81 & 528 & 18.62 & & & \\
\hline
\end{tabular}

Note: Df. Degree of freedom.

\section{CONCLUSION}

In light of the results, the study sample had low levels of anxiety, depression, and insomnia that is explained by the rapid growth in Saudi Arabia of different fields and sectors, and there are rapid shifts and changes that Saudi citizens are witnessing since the establishment of the Saudi 2020 vision. The Kingdom aims to build a flourishing country where all individuals have the opportunity to achieve their goals and is striving to be the first to provide opportunities for everyone through education, training, and high-quality services. Recruitment opportunities, health, housing, and entertainment are examples of many sectors that are supported. These findings may be a result of Saudi Arabia's economic and political stability and advancement in many sectors. Ensuring happiness and physical, psychological, and social well-being of citizens is a top priority. Therefore, a country vision is important; it promotes building a society in which citizens can live a healthy lifestyle and have an attractive, positive environment that results in positive feelings and high levels of psychological happiness.

The researchers also attribute this result to the nature of Saudi society in which the family is considered the foundation of society and provides support to family members. It is the strong support system within the Saudi culture that plays a major role in relieving psychological stress during hard times and stressful events. This is evidenced by the interaction between individuals, which is closely related to adaptation and mental health. Researchers also explain this result by referring to the Islamic characteristics of believing in the judiciary and destiny, and the necessity of recognizing both calamities and privileges that affect a person, and that it is a matter of testing and scrutiny. It is a strong belief within the culture that negative life events and times of distress and harm should be overcome through patience, prayer, and good deeds. It is the Saudi society's culture and religious values which motivate individuals to be optimistic and proactive, to expect the best, and to spread hope during crises and hard times. It is the strong beliefs in society that empower individuals and grant them the ability to overcome catastrophic events. Some of the traits in the Saudi culture is to plan a prosperous future with self-acceptance, which raises the level of psychological well-being. It is religion and belief systems that strongly guide individuals in Saudi Arabia. 
Previous studies have indicated that females are more likely to have higher anxiety levels compared to males. Several factors have been identified that explain the difference. Regarding the study sample, it is important to take into consideration that females in Saudi have been empowered due to the emergence of the 2030 Saudi Vision. Women have more work opportunities and leadership roles that were not fully established previously. Such a shift in society may have impacted women in many ways, one of which could be increased levels of anxiety. Women may have more responsibilities in their lives that go beyond domestic and familial duties. Women now are accepted in nearly every sector. During the pandemic, women may have found it challenging to achieve a balance between entertaining and caring for their families and working remotely.

One reason for increased anxiety and depression could be that individuals with lower levels of education have limited job opportunities, and this also applied before the pandemic. It could be that less educated people may have recurring thoughts regarding their income, families, and job opportunities. The pandemic caused extreme precautionary measures to be brought in to control the spread of the disease. Many companies and sectors encourage remote working, but many others were left with no jobs or had their businesses shut down totally. This has not only strongly impacted the Saudi economy but economies around the world.

In our study, we found that younger individuals are more likely to have higher anxiety and depression, which may be due to several factors, such as thoughts about their futures and the pressure to prove their worth to their families. In accordance with the Saudi Vision 2030, ambitions and expectations could place a burden on younger people to be educated, find work, and rely on themselves. Results suggest that students are more likely to be anxious compared to employers in private and public sectors. This could be due to the cultural expectation to succeed in school and have an income. According to the General Authority for Statistics (GAS) (2020), the number of Saudis in the age range of $15-34$ who are in employment has reached $57.7 \%$ of overall Saudis. In addition, the number of Saudi workers in the $15-24$ age range has reached $70.8 \%$ for males and $37 \%$ for females who are also expected to be students at school. This could explain the increase in anxiety and depression in students compared to others. It is important to note that the Saudi workers in the $25-34$ age range have reached $92 \%$ for males and $53 \%$ for females.

Finally, the study suggests that there is a positive correlation between depression, anxiety, and sleep disorder. Previous studies have reported similar findings in which there is a strong association between these factors.

\section{LIMITATIONS AND FUTURE DIRECTIONS}

Our results demonstrate that investigating the psychological impact of the pandemic provides an opportunity to examine the relationship between mental disorders and life events. However, the current study has limitations that need to be addressed. First, the response rate was moderate and this is usually the case with research in relation to disasters (Logue, Melick, \& Hansen, 1981). Second, the number of female participants was much higher than males, which is a result of the predominantly female workplace. Future studies should examine different psychological reactions to epidemics that are not limited to depression, anxiety, or insomnia.

Funding: This research was funded by the Deanship of Scientific Research at Princess Nourah bint Abdulrahman University through the Fast-track Research funding Program.

Competing Interests: The authors declare that they have no competing interests.

Acknowledgement: Both authors contributed equally to the conception and design of the study.

\section{REFERENCES}

American Psychiatric Association. (2013). Diagnostic and statistical manual of mental disorders (DSM-5®): American Psychiatric Pub. 
Baglioni, C., Battagliese, G., Feige, B., Spiegelhalder, K., Nissen, C., Voderholzer, U., . . Riemann, D. (2011). Insomnia as a predictor of depression: A meta-analytic evaluation of longitudinal epidemiological studies. Journal of Affective Disorders, 135(1-3), 10-19.

Chen, N., Zhou, M., Dong, X., Qu, J., Gong, F., Han, Y., . . Wei, Y. (2020). Epidemiological and clinical characteristics of 99 cases of 2019 novel coronavirus pneumonia in Wuhan, China: A descriptive study. The Lancet, 395(10223), 507-513. Available at: https://doi.org/10.1016/s0140-6736(20)30211-7.

Chen, Q., Liang, M., Li, Y., Guo, J., Fei, D., Wang, L., \& Zhang, Z. (2020). Mental health care for medical staff in China during the COVID-19 outbreak. The Lancet Psychiatry, 7(4), e15-e16. Available at: https://doi.org/10.1016/s22150366(20)30078-x.

Crawley, S. A., Caporino, N. E., Birmaher, B., Ginsburg, G., Piacentini, J., Albano, A. M., . . Rynn, M. (2014). Somatic complaints in anxious youth. Child Psychiatry \& Human Development, 45(4), 398-407.

Drake, C. L., \& Pillai, V. (2017). Phenotypic characteristics of Insomnia disorder. Encyclopedia of Sleep, 193-198. Available at: https://doi.org/10.1016/B978-0-12-809324-5.01016-6.

Gallagher, M., Prinstein, M. J., Simon, V., \& Spirito, A. (2014). Social anxiety symptoms and suicidal ideation in a clinical sample of early adolescents: Examining loneliness and social support as longitudinal mediators. Journal of Abnormal child Psychology, 42(6), 871-883. Available at: https://doi.org/10.1007/s10802-013-9844-7.

General Authority for Statistics [GAS]. (2020). Population characteristics survey 2017. Riyadh: General Authority for Statistics.

Harris, K., Spiegelhalder, K., Espie, C. A., MacMahon, K. M., Woods, H. C., \& Kyle, S. D. (2015). Sleep-related attentional bias in insomnia: A state-of-the-science review. Clinical Psychology Review, 42, 16-27. Available at: https://doi.org/10.1016/j.cpr.2015.08.001.

Ho, C. S., Chee, C. Y., \& Ho, R. C. (2020). Mental health strategies to combat the psychological impact of COVID-19 beyond paranoia and panic. Ann Acad Med Singapore, 49(1), 1-3.

Holshue, M. L., DeBolt, C., Lindquist, S., Lofy, K. H., Wiesman, J., Bruce, H., . . Pallansch, M. A. (2020). First case of 2019 novel coronavirus in the United States. New England Journal of Medicine, 382(10), 929-936. Available at: https://doi.org/10.1056/NEJMoa2001191.

Koranyi, N., Meinhard, M., Bublak, P., Witte, O. W., \& Rupprecht, S. (2018). Automatic affective responses towards the bed in patients with primary insomnia: Evidence for a negativity bias. Journal of Sleep Research, 27(2), 215-219. Available at: https://doi.org/10.1111/jsr.12591.

Krejcie, R. V., \& Morgan, D. W. (1970). Determining sample size for research activities. Educational and Psychological Measurement, $30(3), 607-610$.

Kyle, S. D., \& Espie, C. A. (2014). The HUNT continues and gathers pace: Shedding light on the relationship between insomnia and ill health. Journal of Sleep Research, 23(3), 121-123.

Li, Q., Guan, X., Wu, P., Wang, X., Zhou, L., Tong, Y., \& Feng, Z. (2020). Early transmission dynamics in Wuhan, China, of novel coronavirus-infected pneumonia. New England Journal of Medicine.

Logue, J. N., Melick, M. E., \& Hansen, H. (1981). Research issues and directions in the epidemiology of health effects of disasters. Epidemiologic Reviews, 3(1), 140-162. Available at: https://doi.org/10.1093/oxfordjournals.epirev.a036231.

Morin, C. M., Belleville, G., Bélanger, L., \& Ivers, H. (2011). The Insomnia severity index: psychometric indicators to detect insomnia cases and evaluate treatment response. Sleep, 34(5), 601-608.

Nutt, D., \& Ballenger, J. (2007). Anxiety disorders. Massachusetts: Blackwell Science.

Ohayon, M. M. (2002). Epidemiology of insomnia: What we know and what we still need to learn. Sleep Medicine Reviezws, 6(2), 97-111.

Prince, M., Patel, V., Saxena, S., Maj, M., Maselko, J., Phillips, M. R., \& Rahman, A. (2007). No health without mental health. The Lancet, $370(9590), 859-877$.

Saudi Center for Disease Prevention and Control. (2020). Novel corona virus (2019-nCoV) infection guidelines V1.o. Kingdom of Saudi Arabia: Saudi Center for Disease Prevention and Control Ministry of Health. 
Simpson, H. B., Neria, Y., Lewis-Fernández, R., \& Schneier, F. (2010). Anxiety disorders: Theory, research and clinical perspectives: Cambridge University Press.

Spitzer, R. L., Kroenke, K., Williams, J. B., \& Löwe, B. (2006). A brief measure for assessing generalized anxiety disorder: The GAD-7. Archives of Internal Medicine, 166(10), 1092-1097. Available at: https://doi.org/10.1001/archinte.166.10.1092.

Testa, A., Giannuzzi, R., Sollazzo, F., Petrongolo, L., Bernardini, L., \& Daini, S. (2013). Psychiatric emergencies (part I): Psychiatric disorders causing organic symptoms. European Review for Medical and Pharmacological Sciences, 17 (Suppl 1), 55-64.

Woodgate, R. L., Zurba, M., Edwards, M., Ripat, J. D., \& Rempel, G. (2017). The embodied spaces of children with complex care needs: Effects on the social realities and power negotiations of families. Health \& Place, 46, 6-12. Available at: https://doi.org/10.1016/j.healthplace.2017.04.001.

World Health Organization. (2020). Coronavirus disease 2019 (COVID-19): Situation report. 72.

Wuhan City Health Committee (WCHC). (2020). Wuhan municipal health and health commission's briefing on the current pneumonia epidemic situation in our city 2019 [updated 31 December 201914 January 2020]. Retrieved from: http://wjw.wuhan.gov.cn/front/web/showDetail/2019123108989.2. European Centre for Disease Prevention and Control (ECDC). Risk.

Yang, X., Yu, Y., Xu, J., Shu, H., Liu, H., Wu, Y., \& Shang, Y. (2020). Clinical course and outcomes of critically ill patients with SARS-CoV-2 pneumonia in Wuhan, China: A single-centered, retrospective, observational study. The Lancet Respiratory Medicine, 8(5), 475-481. Available at: https://doi.org/10.1016/s22 13-2600(20)30079-5.

Views and opinions expressed in this article are the views and opinions of the author(s), Humanities and Social Sciences Letters shall not be responsible or answerable for any loss, damage or liability etc. caused in relation to/arising out of the use of the content. 